Notas sobre a noção de transcendência em Heidegger: um modo de pensar a questão pelo sentido de ser

\title{
Notas sobre a noção de transcendência em Heidegger: um modo de pensar a questão pelo sentido de ser
}

\section{Notes on the notion of transcendence in Heidegger: a way to think about the question the meaning of being}

\author{
THAYLA MAGALLY GEVEHR ${ }^{29}$
}

Resumo: A questão condutora de Ser e Tempo (1927) é a questão pelo sentido de ser. Nessa obra, Heidegger pensa demoradamente esse ente que nós mesmos somos - Dasein (ser-o-aí) - o âmbito da questão pelo sentido de ser, o ente que compreende ser, o ente de caráter ôntico-ontológico, isto é, o ente que abre mundo e se encontra "no mundo", mas que, mesmo se relacionando com os entes, estando meio a eles, é marcado por uma diferença constitutiva em relação aos entes simplesmente dados. Dois anos mais tarde, com a publicação da conferência Sobre a Essência do Fundamento (1929), essa mesma temática reaparece, mas sob outro aspecto, digamos assim. Ali, o filósofo alemão mostra que a questão pelo fundamento (pelo ser dos entes) só pode ser colocada "adequadamente" se tiver como âmbito a transcendência. Pensar um modo "adequado" significa pensar a questão visando a diferença ontológica (diferença entre ser e ente) em vez da presentificação do fundamento. Apesar destes temas (fundamento e transcendência) terem sido tratados, de algum modo, na obra de 1927, aqui, na Conferência de 1929, parecem encontrar mais "vigor". Nesta, transcendência é vista como a constituição fundamental do ser-aí. É o modo por que podemos entender "mundo", porque ser transcendência, em sentido heideggeriano, é ser ser-no-mundo. Isto significa, grosso modo, que ser-aí, o ente que lida com o sentido de ser, ultrapassa (transcende) compreensivamente todos os entes sem se perder em meio a eles. Por poder ultrapassar e se manter um mesmo, isto é, ser mesmidade e permitir alteridade, mostra-se, entre outras coisas, como "o" mundo, enquanto lugar para todos os entes e como o espaço para a questão pelo fundamento - um

\footnotetext{
${ }^{29}$ Ex-acadêmica bolsista do Grupo PET/Filosofia da UNIOESTE. Atualmente cursa o Programa de Mestrado na mesma instituição.
} 
espaço que não busca a presentificação do fundamento, mas que permanece a e na pura diferença (ontológica).

Palavras-chave: Ser-aí. Transcendência. Ser-no-mundo. Fundamento.

Abstract: The guiding question of Being and Time (1927) is the question the sense of being. In this work, Heidegger thinks, lingeringly, that being that we ourselves - Dasein - the scope of the question for the sense of being, the entitie who understands being, the ente of ontic-ontological character, that is, the ente which opens the world and is "in the world", but that even if relating with the entities, standing among them, is marked by a constitutive difference from the entities just data. Two years later, with the publication of the conference About the Essence of the Foundation (1929), the same thematic reappears, but in another aspect, say so. Here the German philosopher shows that the question at foundation (the being of entities) can only be placed "properly" if as ambit transcendence. Think a "proper" way means think the question with a view to ontological difference (difference between being and entitie) instead of the foundation presentification. Despite these themes (foundation and transcendence) have been treated in some way in the work of 1927 , here in the 1929 Conference, seem to find more "vigor". This, transcendence is seen as the fundamental constitution of Dasein. Is the way by which we can understand "world" because being transcendence in Heidegger's sense, is to be being in the world. This means, roughly, that being-there, the one who deals with the sense of being, exceeds (transcend) comprehensively all entities without getting lost among them. To be able to overcome and remain the same, i.e. being sameness and allow alterity, it is shown, among other things, as "the" world as the place for all beings and how the space to the issue by the foundation - one space that does not seek presentification the foundation, but that remains to and in pure difference (ontological).

Keywords: Dasein. Transcendence. Being-in-the-world. Foundation.

Sobre a Essência do Fundamento, de 1929, conferência proferida dois anos após a publicação de Ser e Tempo, "nomeia a diferença 
Notas sobre a noção de transcendência em Heidegger: um modo de pensar a questão pelo sentido de ser

ontológica”. É o que afirma Heidegger, no Prefácio à terceira edição (1949). Em vista dessa nomeação, não devemos nos esquecer, primeiramente, que a diferença entre ser e ente constitui a base do projeto filosófico heideggeriano. Em Ser e Tempo, a diferença ontológica consta como pano de fundo amplo, servindo à colocação e compreensão da questão pelo sentido de ser. De modo muito geral, a questão pelo sentido de ser aparece e só pode aparecer mediante a compreensão prévia da diferença entre o aparecer e o que aparece (entes, estados e condições ônticas). Compreender a diferença nada tem a ver com algo que homem possa elaborar ou mesmo operar logicamente; qualquer elaboração ou operação lógica é posterior à diferença ontológica, que fundamenta a compreensão de ser. Com isso, afirma-se que não é o homem quem diferencia ente e ser, como se fossem duas esferas totalmente opostas, para as quais se pudesse apontar, caracterizando suas diferenças: "a diferença ontológica nada tem de apreciação ou distinção racional (seja lógica, categorial ou transcendental) entre o ser e a entidade. (HEIDEGGER, 2003), visto não se tratar de "uma representação do ser e do ente segundo uma diferença” (KAHLMEYER-MERTENS, 2014, p. 190). Não se trata da diferença "entre" dois campos, muito menos de algo a ser observado eventualmente, ou alcançado pela via do conhecimento intelectivo. Como dissemos, a diferença ontológica está à base da compreensão de ser, e, por isso, do sentido em geral; possibilita tanto o advento do ente enquanto ente quanto do ser enquanto tal, já que não haveria "um e outro" senão desde o acontecimento dessa diferença. Quando se fala em compreensão, na filosofia heideggeriana, aponta-se para Dasein ${ }^{30}$ -

${ }^{30}$ Heidegger escolhe, para o ente que nós mesmos somos, o termo "Dasein", que significa, em alemão, existir, no sentido de ser simplesmente dado, de acontecer aí. A 
âmbito em que todas as coisas aparecem com sentido, onde pode surgir a questão pelo sentido de ser, âmbito desde onde a diferença ontológica acontece e pode ser expressa, porque Dasein é a própria diferença.

O tratamento da questão do ser, em Ser e Tempo, se diferencia muito do modo como a história da filosofia a estabeleceu e investigou. A questão se caracterizou pela busca de uma determinação do fundamento. Isto levou a que não se considerasse a diferença ontológica, e mesmo a que não se perguntasse pelo âmbito em que a questão pelo ser pode fazer sentido. A proposta heideggeriana foi, então, a de retomar a questão, a fim de elaborar o que ele denominou de "ontologia fundamental". Embora a investigação de Heidegger emerja do solo da história da filosofia, e ainda que isto tenha sido, por alguns, considerado o solo renovado de uma ontologia "regional" (aquela que considera apenas uma região do ser), seu projeto visa, efetivamente, a destruição das ontologias assim tomadas, uma vez que todas elas procuram a determinação do fundamento, portanto "sem partir da" ou "chegar" à diferença ontológica. Destruir, porém, não significa acabar com a história da filosofia, mas desconstruir suas bases para erigir uma ontologia que dê conta da questão pelo sentido de ser: uma ontologia fundamental. Tal construção, no entanto, será sempre em vista daquela (ontologia, ontologia regional); não buscando um fundamento ou um 'mais ente' para a sustentação da realidade, mas perguntando pelo sentido de ser - onde toda a história da filosofia se movimentou sem reconhecer ou sem tomar como pertinente a questão.

escolha de um vocábulo usual tem por causa sua composição: Da-sein (ser-aí), ser o "lugar" (o aí) dos demais entes. 
Notas sobre a noção de transcendência em Heidegger: um modo de pensar a questão pelo sentido de ser

A exigência de colocar "adequadamente" a questão pelo sentido de ser, de perguntar pelo fundamento mediante a diferença ontológica, exige, conjuntamente, um método adequado. Não trataremos, aqui, do método fenomenológico fundamental, tematizado no parágrafo 7 , de Ser e Tempo. Isto quer dizer que não pensaremos a questão pelo sentido de ser através da exigência do método, mas pensaremos apenas o "lugar" em que ela tem sentido. Faremos isso a partir da análise da transcendência, que é a constituição fundamental do ser aí. A escolha de tratar desse modo a presente problemática se justifica como possível, em certa medida, não só porque o ser-aí é o âmbito para a questão pelo sentido de ser e porque ele se "revela" como transcendência, como já dissemos, mas, também, porque, em Sobre a Essência do Fundamento, Heidegger afirma que a transcendência é "o âmbito da questão pela essência do fundamento" (1979b, p. 98). Nosso objetivo é, dessa forma, entender a relação entre ser-aí, transcendência e fundamento.

Para que cumpramos com a tarefa que nos impomos, trataremos, num primeiro momento, do modo mais geral em que transcendência foi compreendida; num segundo momento, pensaremos em que sentido ela (transcendência) pode ser vista como constituição fundamental do ser-aí; depois nos encaminharemos para o que Heidegger chamou de transcendência como ser-no-mundo e, por fim, tentaremos mostrar, mais detidamente, qual é a relação da transcendência, enquanto lugar para a questão pelo sentido de ser, com a questão pelo fundamento.

\section{Transcendência como ultrapassagem}

Heidegger mostra, em Sobre a Essência do Fundamento, que, 
num sentido tradicional, transcendência tem a ver com ultrapassagem espacial de algo. Isto significa que há um ente que ultrapassa e um ente que é ultrapassado. Dizemos que algo foi transcendido quando um ente foi ultrapassado e quando o ente que ultrapassa traz consigo uma representação do ente ultrapassado espacialmente e do espaço percorrido. Esse pensamento, contudo, acarreta alguns problemas. Não sabemos qual é a conexão entre aquele que ultrapassa e aquilo que é ultrapassado; também não sabemos como isto pode chegar mesmo a acontecer, já que há um ente específico que pode, de fato, ultrapassar e representar enquanto há outro ente que só pode ser ultrapassado e representado - mas não se sabe nada do como, do âmbito em que já estão um para o outro abertos numa "ultrapassabilidade". Em vista desses problemas, afinal legados pela tradição, transcendência não foi pensada como uma simples superação espacial, mas como horizonte em que a ultrapassagem acontece. A estrutura formal desse pensamento pode ser vista da seguinte maneira: (i) o ente que é ultrapassado, (ii) o ente que ultrapassa e (iii) o horizonte em que a ultrapassagem se dá, como possibilidade de que um alvo ou fim seja atingido. Temos, na transcendência concebida como tal horizonte da ultrapassagem, o âmbito em que sujeito e objeto podem aparecer juntos: sujeito é, nesse sentido, aquele ente que transcende na medida em que ultrapassa o objeto surgido num horizonte; é aquele ente que se move em direção ao além, no sentido de buscar o que está adiante, à frente, situado noutro lugar que não o ocupado. Ultrapassar (transcender) seria, então, um dos comportamentos do homem, sempre que for identificado com o sujeito (pois este pode ser um ente supremo ou o Espírito absoluto, p.ex.); é ele quem vai em direção ao ente e, por isso, transcende-o no retorno para si. Nesse comportamento (de ultrapassagem) há o que é 
Notas sobre a noção de transcendência em Heidegger: um modo de pensar a questão pelo sentido de ser

transcendido (objeto) e o horizonte em que a transcendência acontece (o ser do sujeito). Com isso, no entanto, não ficam claros o modo de ser do sujeito que realiza a ultrapassagem, o modo de ser do ente ultrapassado (o objeto), e muito menos a possibilidade de um ser horizonte do outro (o "onde" e em-direção-a-quê acontece a ultrapassagem) ou a relação entre os "três" (ou dois?).

Ainda que o sentido formal de transcendência tente esclarecer a conexão entre sujeito e objeto a partir da noção de horizonte de ultrapassagem, a origem e o modo da ligação não são claros. Aquilo que permite que o horizonte apareça como tal, que permite o encontro de um sujeito qualquer com um objeto qualquer, aquilo que determina a transcendência como possível a um ente específico (o sujeito) e a origem da diferenciação desses três momentos implícitos na ultrapassagem - tudo isto permanece na obscuridade. Isto significa que não adianta falar em espaço percorrido, horizonte em que um alvo é atingido, um em vista do que algo se dá, sem se perguntar pelo âmbito e estrutura ontológica prévia em que todas essas instâncias apareçam como pertencentes à transcendência, como pertencente a um ente específico (neste caso em que parece concernir a um, o "sujeito", a capacidade de alcançar, ultrapassar, compreender o outro). Diante dessa obscuridade e em contraposição a essas significações, Heidegger mostrará que o horizonte em que algo aparece como tal não pode ser determinado por qualquer ente. Apesar de um animal, por exemplo, poder percorrer um espaço, ter uma direção para ir, ele não compreende ser, isto é, animal não se compreende como animal, não se compreende como aquele que vai ao encontro de outro ente para ultrapassá-lo, não compreende o próprio ultrapassar como ultrapassar, ao menos à medida que não se tome como o ente que é e não se diferencie expressamente do ente que ele não é, podendo retornar a si 
depois de compreender/ultrapassar o outro. Não há um "a si, desde outro". Por isso, transcendência, em sentido heideggeriano, tal como expresso em Sobre a Essência do Fundamento,

[...] refere-se àquilo que é próprio do ser-aí humano e isto não, por certo, como um modo de comportamento entre outros possíveis de vez em quando posto em exercício, mas como constituição formal deste ente, que acontece antes de qualquer comportamento. Não há dúvida, o ser-aí humano, enquanto existe "espacialmente", possui, entre outras possibilidades, também a de ultrapassar um precipício. A transcendência, contudo, é a ultrapassagem que possibilita algo tal como existência em geral e, por conseguinte, também um movimentar- "se"-no-espaço (HEIDEGGER, 1979b, p. 104. grifo do autor).

Transcendência não é mero comportamento ôntico, mas constituição ontológica do ser-aí. Pensando dessa forma, ficamos impossibilitados de falar num abismo que separa um ente (um sujeito qualquer) de outro (um objeto qualquer) e do horizonte no qual a ultrapassagem se dá como um meio universal em que sujeito e objeto flutuam. Ultrapassar não é mais um comportamento possível a um homem imerso em um mundo local, mas a constituição fundamental de seu ser enquanto ser-aí; é o modo como ele acontece, o que possibilita e determina todo e qualquer comportamento ôntico (transpor espacialmente uma barreira, superar uma distância, superar uma dor, compreender um evento, entender uma equação etc). Ser-aí coincide com o horizonte mesmo, já que seu ser é a efetividade desse ultrapassar.

\section{Transcendência como constituição fundamental do ser-aí}


Notas sobre a noção de transcendência em Heidegger: um modo de pensar a questão pelo sentido de ser

Quando falamos em transcendência como constituição fundamental do ser-aí, portanto, não estamos apenas deixando de lado uma terminologia (a de sujeito e objeto) e assumindo outra. $\mathrm{O}$ decisivo na clarificação de transcendência é a compreensão de que ser-aí não é um sujeito separado do objeto, que existe independente dele, e que, no encontro com o objeto, traria consigo, "na consciência", uma representação objetiva. Ser-aí é transcendência. Não se trata da representação que o sujeito traz consigo, justamente porque não há dois itens ou "algos" separados, encontrados um ao lado do outro, que se relacionam ou podem se relacionar eventualmente; ser transcendência é já ser previamente junto ao ente, é ser o horizonte de sentido de todo e qualquer ente. Ser junto a quer dizer: ser o espaço ontológico em que o ente e todas as relações já sempre acontecem ou são possíveis. Ser-aí não cria o ente; mas somente no horizonte de doação de sentido que é o ser-aí algo como "ente" tem sentido. A partir da concepção heideggeriana de transcendência como modo de ser fundamental do ser-aí, do fato de não representarmos simplesmente dois entes, um ao lado do outro (o sujeito frente ao ente a ser transcendido), cabe perguntar se é possível falar em transcender e se há um transcendido. Antes que possamos responder a essa pergunta, porém, precisamos esclarecer ainda um pouco mais o modo de ser do ser-aí e o que sua determinação na analítica existencial tem a ver com transcendência.

O modo de ser do ente designado como "ser-aí" é caracterizado, em Ser e Tempo (parágrafos 9 e 12, p.ex.), como existência (Existenz). Diversamente da tradição, que entendeu Existenz como a "existência de um ente em contraste com a sua essência” (INWOOD, 2002, p. 58), o filósofo afirma que "a essência do ser-aí está em sua existência" (HEIDEGGER, 2011, p. 85). Não se trata, aqui, da dualidade "existência 
e essência"; quando falamos em ser-aí, já não lidamos com dualidades, mas com sentido de ser, com âmbito de compreensão. Não cabe, por isso, pensar que ser-aí "tem uma essência" (contraposta à sua existência), ou que "a existência precede a essência”, tal como pensou Sartre. Ser-aí não existe primeiro e, então, vai modulando a sua essência conforme existe ${ }^{31}$. Existenz - ex (para fora) $e$-sistere (insistir em ser) - é a característica fundamental desse ente que nós mesmos somos; apenas ser-aí existe. Isto foi claramente exposto por Heidegger na introdução aposta, em 1949, à conferência Que é Metafísica?, de 1929:

[...] o ente que é ao modo da existência é o homem. Somente o homem existe. O rochedo é, mas não existe. A árvore é, mas não existe. $\mathrm{O}$ anjo é, mas não existe. Deus é, mas não existe. A frase: "Somente o homem existe" de nenhum modo significa apenas que o homem é um ente real, e que todos os entes restantes são irreais e apenas uma aparência ou a representação do homem. A frase: "O homem existe" significa: o homem é aquele ente cujo ser é

\footnotetext{
${ }^{31} \mathrm{Na}$ Carta sobre o Humanismo, Heidegger mostra no que consiste a diferença entre sua filosofia e o pensamento sartriano. Ele diz: "Sartre, ao contrário, assim exprime o princípio do existencialismo: A existência precede a essência. Ele toma, ao dizer isso, existentia e essentia no sentido da Metafísica que, desde Platão, diz: a essentia precede a existentia. Sartre inverte essa frase. Mas a inversão de uma frase metafísica permanece uma frase metafísica. Com essa frase, permanece ele com a Metafísica, no esquecimento da verdade do ser. Pois, mesmo que a Filosofia determine a relação de essentia e existentia, no sentido das controvérsias da Idade Média ou no sentido de Leibniz ou de outro modo, antes de tudo isso, resta, contudo, perguntar a partir de que destino do ser esta distinção no ser de esse essentiae e esse existentiae chega a ser pensada. Permanece desafiando o pensamento o motivo por que $o$ questionamento deste destino do ser nunca foi levantado e por que esta questão pôde ser pensada. Ou é esta situação da distinção de essentia e existentia um sinal do esquecimento do ser?" (HEIDEGGER, 1979d, p. 157).
} 
Notas sobre a noção de transcendência em Heidegger: um modo de pensar a questão pelo sentido de ser

$$
\begin{aligned}
& \text { assinalado pela in-sistência ex-sistente no } \\
& \text { desvelamento do ser a partir do ser e no ser } \\
& \text { (HEIDEGGER, 1979a, p. 59). }
\end{aligned}
$$

Diferente de um ente simplesmente dado (Deus, anjo, rochedo), que não tem sequer a possibilidade de pôr em questão seu ser, ser-aí questiona a si mesmo e está, sempre, imerso na liberdade ${ }^{32}$ de decidir sobre o sentido de seu ser e do ser dos outros ${ }^{33}$. A análise da existência como característica do ser-aí pretende nos levar a uma experiência mais fundamental do ser desse ente que nós mesmos somos, a experiência de concebê-lo como possibilidade de ser, como abertura de ser, como abertura de mundo (COSTA, 2002, p. 23). Neste sentido, o que está em jogo quando Heidegger caracteriza ser-aí como existência é o modo de ser "para fora”, "ex-", o modo de ser "fora”. Mas o que devemos, no fim das contas, entender por este "fora"?

Se entendermos este modo de ser como mera exterioridade em relação a si mesmo e apenas isto, corremos o risco de confundir o seraí com os demais entes e de perder de vista sua constituição fundamental, que não consiste em ser espacialmente alheio ou exterior a qualquer âmbito ôntico, mas em ser o âmbito mesmo de ser,

${ }^{32}$ Liberdade, aqui, não deve ser vista como posterior a existência, no sentido de que ser-aí primeiro existiria e depois decidiria sobre algo do mundo já dado. Ser-aí é caracterizado pela existência. Isto quer dizer que nem existência nem liberdade devem ser interpretados onticamente. Em Sobre a Essência da Verdade, Heidegger afirma que somente "a liberdade, o ser-aí, ek-sistente e desvelador, possui o homem, e isto tão originariamente que somente ela permite a uma humanidade inaugurar a relação com o ente em sua totalidade e enquanto tal" (HEIDEGGER, 1979c, p. 139).

33 "Ser-aí nunca poderá ser apreendido ontologicamente como caso ou exemplar de um gênero de entes simplesmente dados. Pois, para os entes simplesmente dados, o seu "ser" é indiferente ou, mais precisamente, eles são de tal maneira que o seu ser não se lhes pode tornar nem indiferente nem não indiferente” (HEIDEGGER, 2011, p. 86). 
para todo ente. Por outro lado, se apenas nos limitarmos a dizer que ser-aí tem o modo de ser para fora e que nisto mora a diferença dele em relação aos demais entes, não entenderemos, tampouco, o que significa transcendência (a constituição do ser-aí) em sentido fundamental, nem escaparemos de associar ser-aí a um sujeito que se relaciona com objetos sob o modo da representação. Ser para fora significa ser o espaço, o lugar, a abertura "em que" os entes vêm a ser com sentido. Todavia, ser-aí não é só "fora", ele insiste em ser "para fora", isto é, ele é o lugar mesmo para todo sentido. Insistir quer dizer, ontologicamente, permanecer, permanecer sendo o mesmo - aqui, permanecer sendo o espaço de jogo, o "aí". Não se pretende dizer, com isso, que Dasein se decida por ser ou não o espaço, ou se decida por permanecer sendo. Não se trata de um ente simplesmente dado que tem a característica da teimosia em atuar de um determinado modo. Dasein tem o modo de ser da existência. Isto significa que somente ele se relaciona consigo mesmo e com os outros entes sob o modo de compreender ser (compreender a distinção entre ser e ente, e, assim, conceber cada ente como sendo isto ou aquilo: com-preender, abarcar, ser ocasião de ser e sentido). Esta relação só é possível porque, primeiramente, o ser do Dasein é sempre dele mesmo. Ele é responsável por si mesmo, mas também pelo ser dos outros entes; não dá sentido unicamente a seu ser, mas simultaneamente para o ser dos outros. Uma pedra, por exemplo, é e não se relaciona com o solo, não dá sentido a ele (nem vice-versa). Uma pedra está ao lado do solo e apenas isso, ou, talvez, nem mesmo isso, porque a pedra nada sabe do "estar ao lado de". Ser-aí, âmbito de sentido, está junto a, isto é, se relaciona tanto com a pedra quanto com o solo, se relaciona com tudo isso e consigo mesmo, porque só nele todas essas coisas fazem sentido, porque ele é o vínculo e a morada das relações. Quando dizemos, 
Notas sobre a noção de transcendência em Heidegger: um modo de pensar a questão pelo sentido de ser

então, que Dasein insiste em permanecer sendo o mesmo, sendo o espaço, mostramos que Dasein é, a um só tempo, ele mesmo e o espaço para aquilo que ele não é (os entes simplesmente dados). Somente o ser-aí é um "mesmo" - mesmidade implica compreender ser e habitar, por isso, possibilidades enquanto tais. Diante de tal explicação da existência como distinção ontológica do "ente" que é o "aí" para todo ente, pode-se levantar o argumento do solipsismo, uma vez que o ser-aí parece estar sempre só e desconhecer um “outro”. Em Ser e Tempo, de fato, o parágrafo nono dirá que, ao lado do ter que ser (como um ter que existir, no sentido indicado) o ser-aí é "sempre meu" (HEIDEGGER, 2011, p. 42).

Dizer que o ser do ser-aí é sempre dele mesmo, ou, melhor, dizer que o ser desse ente que nós mesmos somos é "sempre meu” não é, porém, o mesmo que afirmar a existência de um "eu" cujo modo de se relacionar consigo mesmo é a posse. Isto seria afirmar que há um ente com tal e tal essência, caracterizado por poder adonar-se dessa essência. Mas ser-aí não é primeiro um simplesmente dado, com tal característica, que a partir dela exerce uma posse. Ser sempre "meu" significa compreender o próprio ser e o ser dos outros como tarefa e possibilidade, já que sempre se trata de um só projeto, em que se dá o encontro: é o mover-se na e como compreensão de ser. Em consequência, na medida em que me relaciono comigo mesmo, como ente em cujo ser está impressa a possibilidade de ser de tal ou tal modo, já sempre decidi não somente a respeito do meu ser, mas a respeito do ser dos outros entes.

Apenas porque ser-aí ex-siste, somente porque é ele mesmo (tem a característica da mesmidade), podemos falar em um "si”, isto é, em relação consigo mesmo e com outro. Um ente simplesmente dado não 
decide sobre si ou sobre os outros, porque não tem compreensão, não tem história e não está lançado em um projeto - isto é, não trata de um "si mesmo", não é, para si mesmo, ele mesmo. Se, porém, ser-aí é quem decide sobre si e sobre os entes simplesmente dados, se é possível falar num ente (ser-aí) diferente de outros entes (os simplesmente dados), por que não posso chamar a um de sujeito e a outro de objeto? Porque sujeito, ao longo da história da filosofia, não foi pensado como âmbito de possibilidade, o "aí", não foi pensado como ente cuja constituição fundamental é a transcendência. Sujeito, tradicionalmente concebido como um simplesmente dado, presente ao lado dos demais entes, que tem características peculiares - razão, linguagem inteligência, consciência etc. - só pode aparecer, diz Heidegger, mediante um âmbito instaurador, ou seja: ele aparece "em" Dasein. Sujeito indica uma falha em tematizar a compreensão de ser e compreendê-la, transformando-a em questão pelos limites do conhecimento. Ser-aí é o âmbito em que as diferenças e as relações são possíveis, em que uma linguagem, mesmo aquela pautada na subjetividade e objetividade, tem lugar. A relação entre sujeito e objeto está fadada ao fracasso de sua determinação mais própria, na medida em que não se consegue pensar, por ela, a própria essência da relação e o que a possibilita. Não se consegue pensar, por ela, a condição de possibilidade da existência. Dasein, no entanto,

[...] existe como um si mesmo a partir de uma referência ao ser, não de maneira autônoma, já que não se lança a si mesmo na existência, ele é tomado pelo ser, atingido por ele, enquanto abertura compreensiva. Ele existe nessa ambiguidade de ser um si-mesmo sem ser um em-si, e, ao mesmo tempo, um si-mesmo cujo ser encontra-se desde sempre fora, enquanto ek-sistência (COSTA, 2002, p. 29). 
Notas sobre a noção de transcendência em Heidegger: um modo de pensar a questão pelo sentido de ser

O modo de ser fora, do Dasein, diz respeito a seu modo de "ser o mundo", ser o sentido ou doar sentido. Ser-aí é ser-no-mundo. Ele não é um sujeito que apreende o mundo (o qual estaria fora do eu, do "si mesmo") e que retorna (para dentro de si) com uma representação do mundo e dos entes que "lá fora" percebeu. Ser-aí é o puro ser-fora, no sentido de ser o lugar ou âmbito para todo vir a ser um ente. Ele é a mesmidade que descobre o outro, a mesmidade que não se confunde com outro. Não se confunde porque seu modo de ser fora, seu modo de ser si mesmo, é transcendência transcendência no sentido existencial, não no de mera ultrapassagem espacialmente tomada. Em outras palavras, transcendência é ser-no-mundo. A ultrapassagem (transcendência) é a constituição fundamental do ser-aí, que lhe permite se reconhecer como um mesmo e como um para fora, como aquele que, em sendo quem é, se distingue previamente e inteiramente dos entes que ele mesmo não é. Transcendência é sempre transcendência do ente que o ser-aí é e do ente desvelado para ele; somente na ultrapassagem, o mesmo pode aparecer como mesmo e outro como outro; nela e somente nela mora a possibilidade de o ente aparecer com sentido. Se afirmamos, porém, que transcendência é ser-no-mundo, temos de entender o que isso significa.

\section{Transcendência como ser-no-mundo}

Transcendência, como vimos, é ultrapassagem. Ultrapassagem não é um comportamento eventual do ser-aí, mas aquilo que acontece antes de qualquer comportamento ôntico, é aquilo que constitui essencialmente seu ser. Tal constituição essencial garante ao ser-aí a possibilidade dele se relacionar com os demais entes enquanto entes e consigo mesmo enquanto compreensão de ser. Por esta constituição, porque é o único que ex-iste (aquele que insisti em ser "fora"), ele diferencia a si mesmo dos entes simplesmente dados, ultrapassando tanto suas próprias determinações ônticas em direção a seu ser, se reconhecendo como um mesmo, como aquele cujo ser não está 
fechado, quanto às determinações ônticas dos demais entes.

Ao dizermos que ser-aí ultrapassa tudo o que é ôntico no ente, em direção ao seu ser, não estamos querendo dizer que ele ultrapassa um ente de cada vez a fim de compreender logicamente ou a fim de representar imagética ou conceitualmente o todo do ente (suas regiões, estratos ou conexões específicas). Não estamos dizendo que ser-aí é um sujeito capaz de compreender e somar todas as compreensões que tem ou recebeu de cada ente particular num todo intelectual ou subjetivo; tampouco que esse todo é intelectual ou subjetivo a ponto de permitir, a priori, que os entes apareçam conectados, ligados ou mesmo totalizados (no sentido de organizados ou passíveis de organização numa totalidade). Ser-aí é âmbito de sentido, é o âmbito que permite o aparecimento do ente. Isto não tem nada a ver com subjetividade, mas com transcendência, que, em Heidegger, não é entendida, no sentido do transcendental kantiano, como a possibilidade do conhecimento a priori, mas como compreensão de ser: ser-aí compreende a si como mesmo e porque é mesmidade é abertura para o aparecimento de um outro. Ser-aí, como ex-istente, como aquele ente que se relaciona e compreende seu ser e dos demais entes, é o mundo, é o âmbito para toda e qualquer relação. Expliquemos melhor.

Tudo aquilo que aparece (os entes) têm sentido porque aparece num contexto de compreensibilidade. Uma coisa, um ente, aparecerá como aquilo que é desde um horizonte de compreensão. Um horizonte de compreensão determinado é um "mundo". Heidegger não chama de mundo a um lugar espacial, uma região do espaço em que as coisas simplesmente presentes aparecem, mas de acontecimento de sentido. Para que algo apareça num horizonte de 
Notas sobre a noção de transcendência em Heidegger: um modo de pensar a questão pelo sentido de ser

sentido, é necessário que haja já compreensão de ser, isto é, diferença ontológica. Um ente compreendido em seu ser, a partir disso, não é um ente conhecido em toda a sua estrutura específica, é um ente cujo sentido se dá desde uma totalidade significativa. Ora, se o ente não está desligado da totalidade que o envolve, então como lidaremos com essa totalidade? Como lidaremos com o ente na totalidade? O que é totalidade?

Em sentido heideggeriano, a totalidade não pode ser tomada como uma soma de entes, que tem um tamanho ou uma amplitude específica. Totalidade não quer dizer a reunião "total", "final" de todos os entes possíveis para o conhecimento ou de todos os entes existentes. Em Heidegger, ela é mutável e pode ser compreendida a cada vez, não como um ente, mas como aquilo que, em cada contexto, o comporta com determinado sentido ${ }^{34}$; na totalidade, o sentido do ente já está, previamente, desvelado. Por exemplo, uma caneta não vai aparecer como caneta desligada de todo o contexto, de todo o horizonte significativo, que a envolve. Só é possível que o ser da caneta seja compreendido porque o contexto em que ela aparece como tal já se deu, já é, como todo, sentido. Esse contexto total, na mesma medida em que é permitido por ser aí, mantém aberta a possibilidade dele se relacionar com o próprio contexto (aberto por ele) e com cada ente específico - aquele cujo modo de ser é ser numa totalidade. "A compreensão dessa totalidade (contexto) que é sempre antecipadora e abarcadora é, porém, ultrapassagem com relação ao mundo" (HEIDEGGER, 1979b, p. 115).

\footnotetext{
${ }^{34}$ A totalidade de um contexto de guerra é diferente da totalidade de um contexto de paz. Cada situação, cada modo pertencente a situação específica, será compreendida desde a totalidade, desde o contexto todo.
} 
Ultrapassagem, em Heidegger, não é um ir em direção a algo a fim de deixá-lo para trás (COSTA, 2012, p. 88). Ser-aí, como aquele cujo modo de ser é transcendência, ultrapassa um ente em direção a uma totalidade. Essa totalidade é o horizonte em que o ente aparece já com sentido. Nenhum ente pode aparecer fora desse horizonte. Quando ser-aí ultrapassa o ente, volta para si mesmo compreendendo tanto o ente ultrapassado (como um simplesmente dado ou como um outro que não ele) quanto a si mesmo. Somente porque ser-aí é um mesmo, pode ser, também, o espaço permissor do aparecimento de outro. Esse espaço, esse "ser fora" do ser-aí, é mundo, é o próprio horizonte.

Mundo, como o horizonte da transcendência, é aquilo a partir do que a presença [ser-aí] se dá a compreender, isto é, no projetar-se compreensivamente em direção a mundo, a presença [ser-aí] vem a si na compreensão de seu ser. Nesse sentido, essa ultrapassagem em direção a mundo é o projeto enquanto possibilidades de ser da presença [ser-aí]: o ente que existe em virtude de ser o seu ser. Nessa perspectiva, enquanto ser-no-mundo, a presença [ser-aí] existe em vista de si mesma e de mundo: é a partir de mundo e em um mundo que ela se compreende e se realiza (COSTA, 2007, p. 88).

Mundo é, pois, uma instância do ser-aí. É aquilo que permanece aberto por ele, mas, ao mesmo tempo, é aquilo que permite que ser-aí se reconheça, a cada vez, como mesmidade e se relacione com os entes. Ser-aí, como aquele ente que se encontra "em meio aos entes", como aquele que se dá e permanece junto aos entes, como aquele que se move no próprio âmbito compreensivo que abre, transcende mundo e retorna a si mesmo, compreendendo-se como mesmidade, compreendendo mundo como diferente de si, embora seja 
Notas sobre a noção de transcendência em Heidegger: um modo de pensar a questão pelo sentido de ser

possibilitado por ele, e compreendendo o ente como tal. Ser transcendência significa, a partir do que foi dito, ser o projeto compreensivo, ser aquele ente que vai compreensivamente em direção a mundo. Este ir não visa o abandono ou um ultrapassamento de mundo, como se ele fosse uma barreira ou uma coisa. Ir em direção a mundo significa reconhecê-lo como âmbito dos entes, como âmbito desde o qual o sentido do ente se dá como permitido por ser-aí, como aquele a partir do qual ser-aí se entende e de "onde" apreende o modo de se comportar e relacionar com o ente (HEIDEGGER, 1979b, p. 115). Esse âmbito dos entes é formado, contudo, por ser-aí: ele é o espaço de possibilidade e de acontecimento de mundo, ele é, como ser-nomundo, aquele que deixa o ente se revelar, ganhar um mundo, entrar no mundo, ser visto desde uma totalidade de significância ${ }^{35}$, e se revela, em igual medida, como si mesmidade.

A ultrapassagem compreensiva do ente é a constituição da mesmidade do ser-aí - aquele que nunca se dá em vista de alguma coisa, mas apenas em vista-de-si-mesmo. Isto quer dizer que ser-aí não vai ao mundo e volta, no sentido de buscar representações, mas que ele é o espaço de presentificação. Na ultrapassagem, ser-aí não permanece na "mera" compreensão do ser do ente com o qual se relaciona, mas retorna a si, como um mesmo. Este retorno não quer dizer um mero ir e voltar com uma representação do ente. Ser-aí ultrapassa o ente compreensivamente. Isto quer significa: ser-aí já compreende e já se move na compreensão. Compreender não quer

${ }^{35}$ Um ente só entra num mundo, isto é, é visto com sentido, porque ser-aí permite. Se uma xícara, por exemplo, pudesse, por si mesma, estar em um mundo, ela teria, como ser-aí, o modo de ser da transcendência. A entrada de um ente num mundo é possibilitada por ser-aí, porque ele permanece o âmbito de sentido, ele é o mesmo e o "fora", ele deixa os entes aparecerem, entrarem em um mundo de significância. 
dizer "representar", mas doar âmbito ao ente, se comportar com o ente desde a doação de sentido. Dito de outra forma: é o ser-aí quem coloca mundo diante de si, porque é âmbito de sentido, porque se move na compreensão de ser. Por ser em vista-de-si-mesmo, é aquele que possibilita, enquanto projeto originário (transcendência), todo o comportamento em relação ao ente. Não faria sentido, diante disso, se a transcendência fosse um movimento que parasse no ente, ou seja, um movimento que não contasse com o retorno do ser-aí a si mesmo. Não faria sentido, porque, primeiro, sem este retorno não há transcendência. É justamente por retornar a si, por ser em vista-de-simesmo e não em vista do ente, que ser-aí abre mundo, que ser-aí é visto como ser no mundo - sem si mesmidade, enquanto estrutura permissora do âmbito dos entes, não há mundo, não há transcendência, não há ser-no-mundo.

\section{Conclusão}

Dissemos, no início desse texto, que a diferença ontológica não é uma operação realizada pelo homem. Dasein, isto é, ser-aí é o irromper da diferença, o âmbito em que compreensão de ser acontece, porque a este âmbito pertence a própria compreensão (sentido). Compreender é, em sentido ontológico, para Heidegger, o modo como ser-aí se relaciona com o ente, é a condição para que o problema do ser (do fundamento) possa ser posta e, portanto, para que o ente possa ser conceituado. Se pudéssemos pensar, então, o motivo por que Heidegger afirma que Sobre a essência do fundamento "nomeia a diferença ontológica", seria, justamente, porque à luz da diferença ontológica uma ontologia que não se mova nos graus de revelação do 
Notas sobre a noção de transcendência em Heidegger: um modo de pensar a questão pelo sentido de ser

ente é possível ${ }^{36}$. Mais: somente à luz da diferença entre ser e ente a questão pelo sentido de ser encontra lugar - ser-aí (Dasein). Tal questão pode encontrar lugar, no ser-aí, porque ele é transcendência e esta se dá como ser-no-mundo. Expliquemos.

A questão pelo sentido de ser só pode aparecer porque ser-aí, enquanto abertura de mundo, se encontra junto aos entes, está em meio aos entes, se relaciona com eles compreensivamente, compreende ser. Ser-aí "abre espaço" para que os entes aconteçam com sentido, ele é o âmbito para que o ente seja como tal, numa totalidade significativa. Os entes só podem aparecer em uma "respectiva totalidade" - mundo - porque ser-aí é transcendência. Ser transcendência significa "ter" (ou ser) o mundo como a totalidade do "em-vista-de-si-mesmo" (HEIDEGGER, 1979b, p. 119). Isto quer dizer, em poucas palavras, que somente porque o ser-aí é vista-de-si-mesmo, ele pode ultrapassar compreensivamente o ente sem se perder em meio a ele; só porque é mesmidade se diferencia dos demais entes e se entende como espaço (como o "fora", como o âmbito) para tudo o que compreende, inclusive para si.

Como a constituição fundamental do ser-aí é transcendência e transcender significa ultrapassar compreensivamente, então mundo, em vista desta constituição fundamental, se dá tanto como totalidade

36 "Um grau característico é, por exemplo, o projeto da constituição do ser do ente, através do qual é, concomitantemente, delimitado um determinado campo (natureza, história) como área de possível objetivação através do conhecimento científico. A prévia determinação do ser (que-ser e como-ser) da natureza em geral se fixa nos "conceitos fundamentais" da respectiva ciência. Nestes conceitos são, por exemplo, delimitados espaço, lugar, tempo, movimento, massa, força, velocidade; todavia, a essência do tempo, do movimento, não é propriamente problematizada” (HEIDEGGER, 1979b, p. 101-102). 
significativa quanto como "aquilo" desde "onde" ser-aí pode se mostrar como mesmidade, como espaço para a alteridade, como compreensão. Neste sentido, no sentido da compreensão, a questão pelo sentido de ser só é possível em ser-aí, porque ele é o espaço da pura diferença, é ele quem compreende ser e quem coloca em jogo tanto o seu ser quanto o dos demais entes na medida em que os compreende, na medida em que seu ser e o ser dos entes já é compreensão, já é, sempre, sentido.

\section{Referências bibliográficas}

COSTA, Denise. O si mesmo e a singularidade da presença. Salvador: Universidade Federal da Bahia, 2007 (Dissertação de Mestrado).

HEIDEGGER, M. Que é metafísica? Tradução de Ernildo Stein. São Paulo: Abril Cultural, 1979a. (Coleção Os Pensadores).

. Sobre a essência do fundamento. Tradução de Ernildo Stein. São Paulo: Abril Cultural, 1979b. (Coleção Os Pensadores).

. Sobre a essência da verdade. Tradução de Ernildo Stein. São Paulo: Abril Cultural, 1979c. (Coleção Os Pensadores).

. Carta sobre o humanismo. Tradução de Ernildo Stein. São Paulo: Abril Cultural, 1979d. (Coleção Os Pensadores).

. Ser e Tempo. Tradução de Marcia Sá Cavalcante Schuback. Petrópolis, RJ: Vozes, 2011.

INWOOD, Michael. Dicionário Heidegger. Tradução de Luísa Buarque de Holanda. Rio de Janeiro: Jorge Zahar, 2002.

KAHLMEYER-MERTENS, Roberto. "Da centralidade do conceito de 'diferença ontológica' em Contribuições à filosofia”. In: Heidegger e sua época 1930-1950. WU, Roberto (Org.). Porto Alegre: Clarinete, 2014, p. 181-196. 